\title{
Pancreatic endocrine tumors
}

\author{
Sylvia L Asa
}

Department of Pathology and Ontario Cancer Institute, University Health Network, University of Toronto, Toronto, ON, Canada

\begin{abstract}
The endocrine cells of the pancreas and their related cells throughout the gastrointestinal tract give rise to a variety of tumors that pose a diagnostic challenge. There has been progress in understanding their histogenesis, morphology, immunohistochemistry, molecular biology and classifications. This review will focus on nomenclature/terminology, classification, the role of immunohistochemistry, molecular advances, including genetic predisposition, and potential therapeutic targets to define the role of pathology in the application of prognostic and predictive markers for this disease. Modern Pathology (2011) 24, S66-S77; doi:10.1038/modpathol.2010.127
\end{abstract}

Keywords: classification; endocrine tumor; molecular genetics; pancreas; predictive markers; staging

The endocrine pancreas is a component of the dispersed endocrine system, a complex group of peptide hormone-secreting or 'neuroendocrine' cells that are dispersed singly and in small clusters throughout the pancreas, gut, lung and other sites, including prostate and ovary. ${ }^{1}$ The neoplasms that arise from these cells range from small benign incidental findings to functional hormone-secreting tumors to aggressive malignancies.

\section{Nomenclature/terminology}

The term 'carcinoid' meaning 'carcinoma like' was originally introduced by Oberndorfer in 1907 to describe these peculiar tumors that resembled cancers, but had unusual clinical behavior. ${ }^{2}$ Use of the term carcinoid has become entrenched in the medical literature, but has been applied to different entities by pathologists and clinicians. Pathologists have traditionally classified well-differentiated endocrine tumors of the lung, gut and pancreas as 'carcinoid tumors,' whereas clinicians have restricted the use of the term to describe the syndrome caused by serotonin excess. Moreover, it became apparent that a 'carcinoid tumor' in one site was not equivalent to a similar tumor in another site and that these tumors, initially thought to be benign, display the full histopathological spectrum from very low- to high-grade malig-

Correspondence: Dr SL Asa, Department of Pathology, University Health Network, 200 Elizabeth Street, 11th floor, Eaton wing, Toronto, ON, Canada M5G 2C4.

E-mail: sylvia.asa@uhn.on.ca

Received 21 May 2010; accepted 31 May 2010 nancy. Thus, the term 'carcinoid' has led to the misunderstanding of the malignant potential of these tumors and the use of the term has been increasingly discouraged in favor of more precise terminology.

Endocrine tumors in the pancreas were originally thought to derive from the islets of Langerhans, hence the previous terminology 'islet cell tumors.' More recent evidence indicates that they actually derive from precursors in the ductal epithelium, so this terminology has been abandoned in favor of 'pancreatic endocrine tumors (PETs).'

The controversy continued with discussions of the appropriateness of 'endocrine' or 'neuroendocrine' to describe these tumors. The cells that comprise these lesions, such as their normal counterparts, express several antigens that are commonly expressed by neuronal elements: neuronspecific enolase (NSE), protein gene product 9.5 (PGP 9.5), chromogranin A, B and C and synaptophysin. ${ }^{3}$ For this reason 'neuroendocrine' has become the preferred designation and the term 'neuroendocrine tumor' (NET) is becoming prevalent for tumors outside the pancreas. ${ }^{4}$ However, in the pancreas the term 'PET' has been recommended by the World Health Organization (WHO). ${ }^{5}$

The mature pancreas contains at least four characteristic neuroendocrine cell types that are usually found together in small clusters within the islets of Langerhans (Figure 1). There are at least 15 discrete neuroendocrine cell types distributed throughout the gastrointestinal tract. There is extensive overlap, for example somatostatin-producing cells are present in both, and during development, gastrin is produced in the pancreas, 

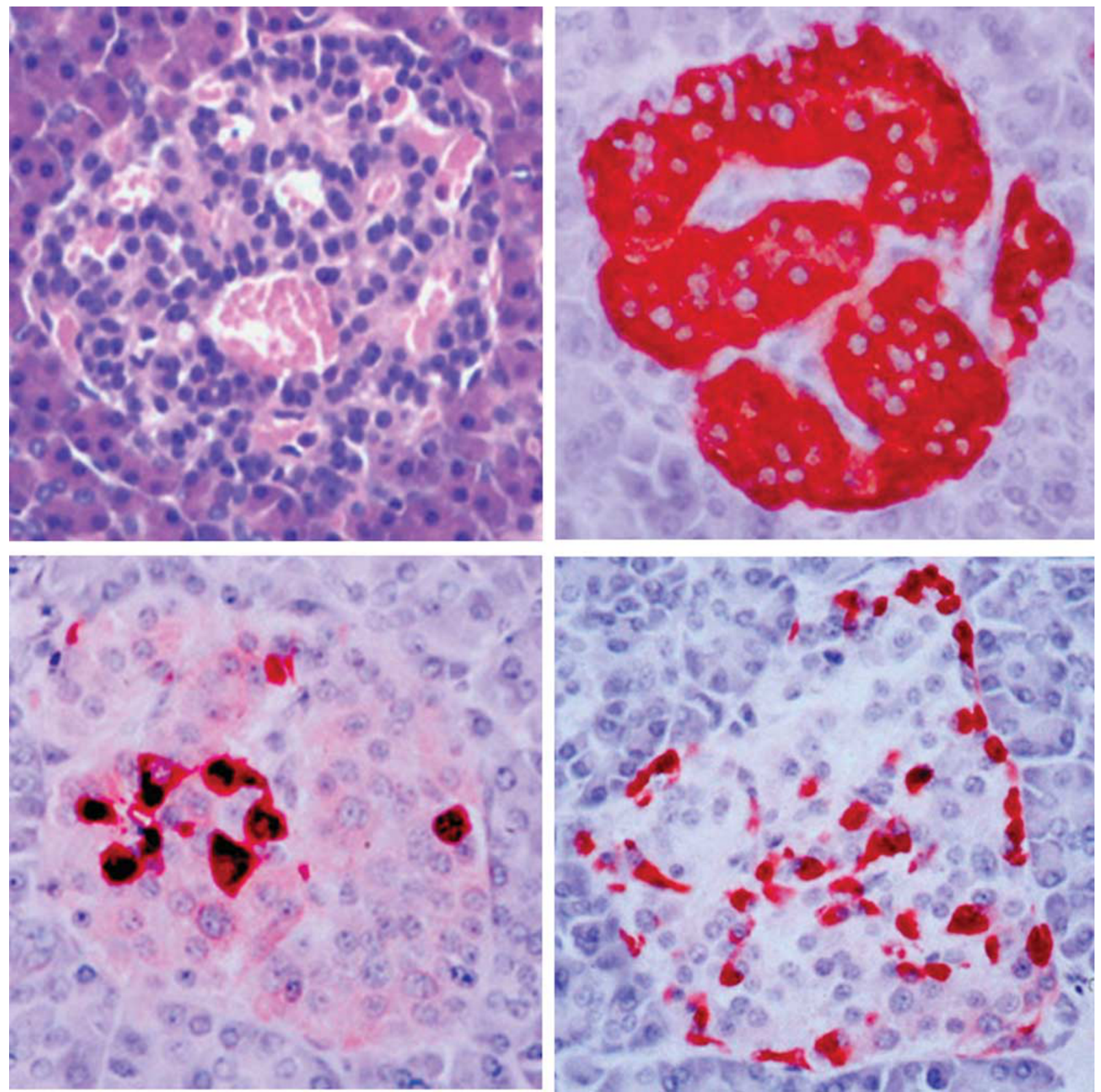

Figure 1 The normal endocrine pancreas. The endocrine pancreas is composed of the islets of Langerhans, small unencapsulated clusters of endocrine cells in a vascular connective tissue (top left). Although they appear homogeneous, the endocrine cells are actually of distinct types arranged in a specific pattern. Insulin-containing B cells (top right) comprise the majority, forming solid tubular structures that are wound into the round islet. They are surrounded by glucagon-containing A cells (bottom right) that form the outer lining of the tubules. Between the two, somatostatin-containing D cells are randomly distributed. PP cells that contain pancreatic polypeptide are found mainly in islets in the head of the pancreas (not shown).

so that any discussion of pancreatic NETs has implications for gastrointestinal NETs.

\section{Epidemiology}

PETs are rare, with an incidence of 1 in 100000 people. They represent approximately $1-2 \%$ of all pancreatic neoplasms, but in some series that number is higher, reaching up to $15 \%$; this may reflect biases in clinical practice referrals. The incidence in autopsy studies has been reported as high as $1.5 \%$; these studies usually identify clinically unrecognized, often asymptomatic and usually small $(<1 \mathrm{~cm})$ lesions. The tumors show no significant gender predilection and occur at all ages, with a peak incidence between 30 and 60 years. $^{5-7}$ Approximately $1-2 \%$ of patients with these tumors have familial syndromes of predisposition, and the genetics of these disorders are discussed below. 


\section{Clinical and biochemical features}

The clinical manifestations of PETs vary depending on whether they are clinically 'functioning,' giving rise to signs and symptoms of hormone excess, or 'non-functioning,' that is, creating no clinical features that prompt a search for hormone production.

The clinical syndromes caused by inappropriate secretion of hormones are different for each hormone produced. Insulinomas that secret excess insulin result in hypoglycemia. Glucagonomas cause a spectrum of features including diabetes mellitus and occasionally a characteristic rash known as 'necrolytic migratory erythema.' The somatostatinoma syndrome is a well described but poorly recognized syndrome that includes diabetes, cholelithiasis and borborygmi. Gastrinomas are associated with the Zollinger-Ellison syndrome, and VIPomas give rise to the disorder known as 'pancreatic cholera.' Other less common tumors can secrete hormones that result in acromegaly, Cushing's syndrome and other unusual disorders.

Approximately $30-40 \%$ of PETs are classified as 'non-functioning' or 'non-syndromic' because they are not associated with distinct clinical manifestations of hormone alterations. These lesions may still produce hormones that are detected by immunohistochemistry or by measurement of circulating levels in the blood. Non-functioning tumors usually become clinically apparent when they reach a size that causes compression or invasion of adjacent organs, or when they metastasize. They may be detected incidentally on abdominal imaging for other reasons. Rarely, they cause pancreatitis.

\section{Diagnosis and classification}

\section{Morphology}

The initial diagnosis of a PET is based on morphological features. ${ }^{8}$ Grossly, these lesions are usually solitary, well-demarcated, tan to pink soft tumors, but they may be hard and gray-white nodules when they exhibit fibrosis or amyloid deposition (Figure 2). Well-differentiated tumors can manifest a diverse range of histological appearances including the common solid nesting pattern (Figure 3a), a trabecular/gyriform pattern (Figure 3b), glandular formations (Figure 3c), tubular-acinar and mixed patterns. Stromal fibrosis (Figure 3d) and amyloid deposition are seen, the latter mainly in insulinomas. The presence of calcification is sometimes noted and when psammomatous in nature is diagnostic of a somatostatin-producing tumor. Less commonly, cystic, papillary and so-called angiomatoid/ angiomatous patterns may also be seen. Another morphological variant is a pancreatic NET with ductules. ${ }^{9,10}$ This is not a mixed neuroendocrineepithelial tumor, but a NET with ductules that are either entrapped as the tumor grows into surrounding normal pancreatic tissue (Figure 3e) or as a result of secondary ductular proliferation occurring as a reactive phenomenon.

The cells have readily recognizable cytological features: round to ovoid cells with eosinophilic, slightly granular cytoplasm and nuclei with a dispersed chromatin pattern ('salt and pepper') and, not infrequently, discernible nucleoli (Figure 3). Occasionally, nuclear pseudoinclusions may be seen. Oncocytic change results in the development of abundant granular eosinophilic cytoplasm because of accumulation of mitochondria (Figure 3f). Clear cell change may be seen focally in oncocytic lesions, or may be diffuse due to extreme lipid accumulation. Unusual tumors may have spindlecell morphology or so-called 'rhabdoid' features that are actually due to perinuclear aggresomes composed of keratin filaments rather than rhabdoid differentiation. ${ }^{11,12}$

Large cell and small cell endocrine carcinomas are high-grade malignancies with high mitotic and Ki-67-labeling indices. Mixed tumors with exocrine

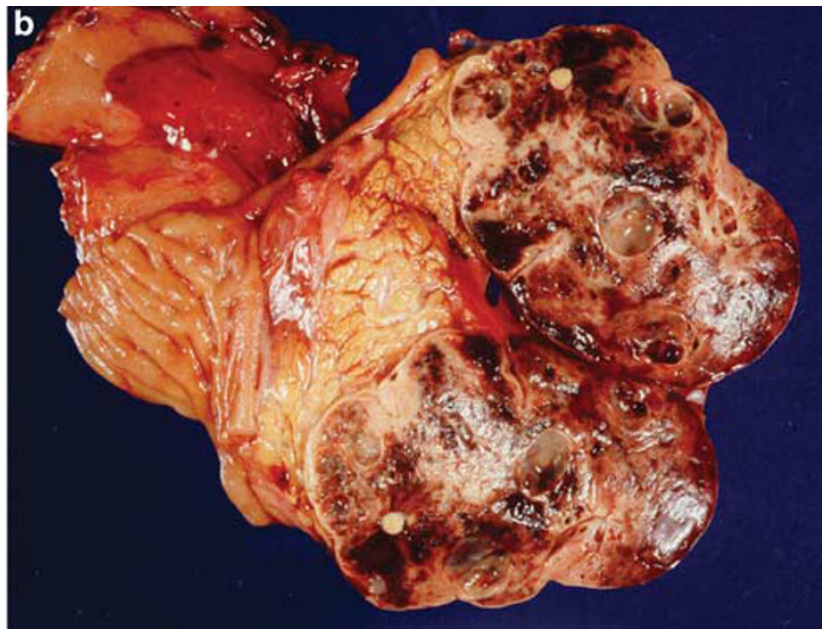

Figure 2 The gross appearance of pancreatic endocrine tumors. (a) These lesions can be firm, fibrotic and pale gray lesions (left) or soft, tan and hemorrhagic (right). (b) Large lesions frequently have areas of cystic degeneration and hemorrhagic necrosis. 

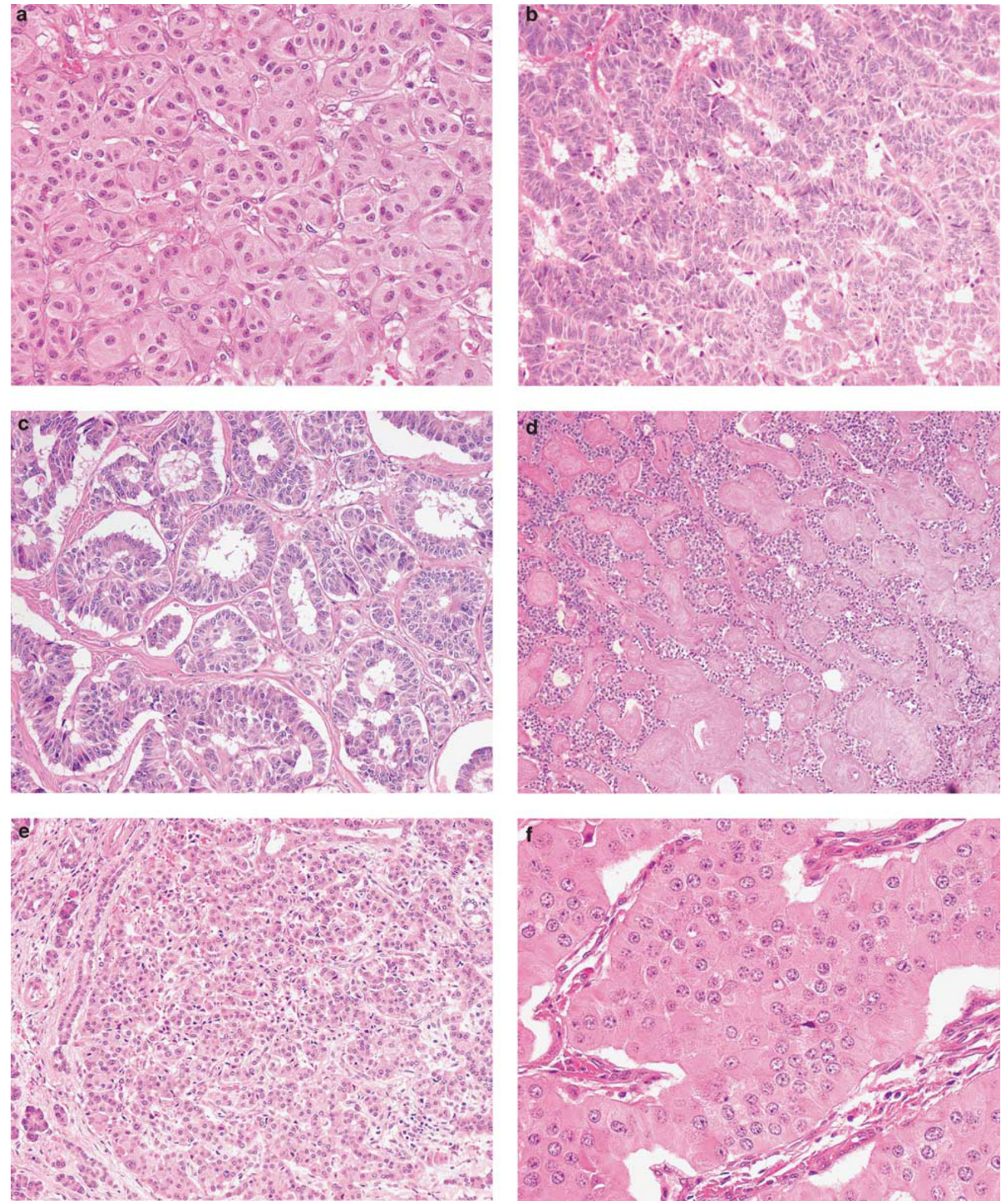

Figure 3 Microscopic variants of pancreatic endocrine tumors. (a) The usual histologic appearance is that of a solid nesting architecture; the tumor cells are round to ovoid with eosinophilic, slightly granular cytoplasm and dispersed nuclear chromatin resembling 'salt and pepper.' Nucleoli are usually prominent and occasional inclusions are seen. (b) Trabecular and gyriform architecture is usually associated with elongated cells that have crowded nuclei. (c) A glandular pattern can mimic exocrine adenocarcinomas. (d) Stromal fibrosis can be very prominent and form the bulk of the tumor mass. (e) Pancreatic endocrine tumors are often found associated with exocrine ducts (left) and are thought to derive from precursor cells in those structures; the presence of ductules within the lesions (top and upper right) may be trapped by expanding tumor or may represent secondary ductular proliferations. (f) Oncocytic tumors are characterized by cells with abundant granular eosinophilic cytoplasm because of accumulation of mitochondria. 
differentiation are aggressive lesions that behave more similar to exocrine than endocrine carcinomas.

\section{Immunohistochemistry}

The currently accepted markers that define neuroendocrine differentiation are synaptophysin (a small vesicle-associated marker) and chromogranin (a large secretory granule-associated marker). ${ }^{13}$ The latter is particularly important as it can be detected in the circulation of patients with these lesions and, therefore, serves as a useful tumor marker for clinical surveillance. ${ }^{14}$ Other markers include PGP 9.5 (a cytoplasmic protein) as well as CD56 and NSE, but the latter two are not considered to be specific for NETs. Recently, antibodies to histidine decarboxylase have been proposed as a valuable diagnostic tool. ${ }^{15}$ Neuroendocrine-secretory protein-55 is a 241 amino-acid polypeptide that belongs to the chromogranin family and is thus located within large dense core secretory granules; ${ }^{16}$ it is thought to stain PETs and distinguish them from gastrointestinal NETs.

The indication for immunolocalization of cellspecific markers and hormones depends on the site and function of the tumor. The functional status and the clinical symptoms of the patient will determine specific markers performed in a particular case. Immunohistochemically detected peptides do not imply that the patient has clinical symptoms, nor does this finding implies that the tumor is functional. However, many patients are not evaluated biochemically for the full spectrum of peptide products of NETs, and the absence of recognizable clinical features may not necessarily reflect the true lack of clinical function, as subtle clinical manifestations may be missed. The identification of hormone products may, in some cases, provide a previously unrecognized tumor marker for surveillance. In addition, the expression of ectopic hormones is suggestive of a more aggressive lesion, and provides the definition of malignancy for some tumors. Understanding of hormone profiles also offers the foundation for localization of small primary lesions in patients with metastases at presentation.

\section{Classification}

Given the variability of cytodifferentiation and the many sites in which NETs develop, it is not surprising that a single classification spanning all body sites does not exist. In 2000, Wick proposed a generic classification for neuroendocrine neoplasia irrespective of the site based on a three-tiered grading system. ${ }^{17}$ Consistent with this proposal, in 2004, the WHO classified PETs into three broad categories as shown in Table $1:^{5}$

1. Well-differentiated endocrine tumor: (i) benign and (ii) uncertain malignant potential.

2. Well-differentiated endocrine carcinoma: lowgrade malignant.

3. Poorly differentiated endocrine carcinoma: highgrade malignant.

Categorization is based on tumor size $(<2 \mathrm{~cm}$ benign $v s \geqslant 2 \mathrm{~cm}$ uncertain malignant potential), perineural or angioinvasion (benign $v S$ uncertain malignant potential), mitotic count ( $<2$ per $10 \mathrm{HPF}$ benign $v s>2$ to 10 per $10 \mathrm{HPF}$ uncertain malignant potential), proliferation index $(<2 \%$ benign $v S$ $\geqslant 2 \%$ uncertain malignant potential), functional status/hormonal syndrome and metastases to lymph nodes or liver (the most common site of distant metastasis) or elsewhere. Tumor necrosis is uncommon in low-grade pancreatic endocrine neoplasms, but is generally regarded as a malignancy-associated feature.

Mitotic count should be based on counting 50 HPF ( $\times 40$ objective) and in the area of highest mitotic activity, and reported as number of mitoses per $10 \mathrm{HPF}$. However, a low mitotic index is of little prognostic value, and many malignant tumors show

Table 1 WHO classification of pancreatic endocrine tumors

\begin{tabular}{|c|c|c|c|}
\hline Classification & $\begin{array}{l}\text { WHO } \\
\text { type }\end{array}$ & Local invasion & Features \\
\hline $\begin{array}{l}\text { Well-differentiated endocrine tumor, benign } \\
\text { behavior }\end{array}$ & 1.1 & Confined to pancreas & $\begin{array}{l}<2 \mathrm{~cm}, \text { no angioinvasion or perineural } \\
\text { invasion, }<2 \text { mitoses per } 10 \mathrm{HPF} \\
\text { Ki67-labeling index }<2 \%\end{array}$ \\
\hline $\begin{array}{l}\text { Well-differentiated endocrine tumor, uncertain } \\
\text { behavior (one or more high-risk features) }\end{array}$ & 1.2 & Confined to pancreas & $\begin{array}{l}\text { One or more of the following features: } \geq 2 \mathrm{~cm} \text {, } \\
\text { angioinvasion, perineural invasion, } 2-10 \\
\text { mitoses per } 10 \mathrm{HPF} \text {; Ki67-labeling index } \\
2 \% \text { or greater }\end{array}$ \\
\hline Well-differentiated endocrine carcinoma & 2 & $\begin{array}{l}\text { Gross local invasion } \\
\text { and/or metastases }\end{array}$ & $\begin{array}{l}\text { Generally shows one or more of the following } \\
\text { features: } \geq 2 \mathrm{~cm} \text {, angioinvasion, perineural } \\
\text { invasion, } 2-10 \text { mitoses per } 10 \mathrm{HPF} \text {; } \\
\text { Ki67-labeling index } 2 \% \text { or greater }\end{array}$ \\
\hline $\begin{array}{l}\text { Poorly differentiated endocrine carcinoma, } \\
\text { benign behavior (small cell carcinoma or large } \\
\text { cell endocrine carcinoma) }\end{array}$ & 3 & $\begin{array}{l}\text { Often widely invasive } \\
\text { or metastatic }\end{array}$ & $\begin{array}{l}\text { High-grade carcinoma with }>10 \text { mitoses per } \\
10 \mathrm{HPF}\end{array}$ \\
\hline
\end{tabular}
cell endocrine carcinoma) 
Table 2 Staging of pancreatic endocrine tumors

\section{TNM}

T-primary tumor (for any $T$, add (m) for multiple tumors)

TX Primary tumor cannot be assessed

T0 No evidence of primary tumor

T1 Tumor limited to the pancreas and size $\leqslant 2 \mathrm{~cm}$

T2 Tumor limited to the pancreas and size $>2 \mathrm{~cm}$

T3 Tumor extends beyond the pancreas, but without involvement of the celiac axis or the superior mesenteric artery

T4 Tumor involves the celiac axis or the superior mesenteric artery (unresectable)

$N$-regional lymph nodes

NX Regional lymph node cannot be assessed

No No regional lymph node metastasis

N1 Regional lymph node metastasis

$M-$ distant metastases

MX Distant metastasis cannot be assessed

Mo No distant metastases

M1 Distant metastasis (indicates the presence of any single or multiple metastases at any distant anatomical site including non-regional nodes)

\begin{tabular}{|c|c|c|c|c|c|}
\hline $\begin{array}{l}\text { Stage Ia } \\
\text { T1, N0 }\end{array}$ & $\begin{array}{l}\text { Stage Ib } \\
\text { T2, No }\end{array}$ & $\begin{array}{l}\text { Stage IIa } \\
\text { T3, No }\end{array}$ & $\begin{array}{l}\text { Stage IIb } \\
\text { T1-3, N1 }\end{array}$ & $\begin{array}{c}\text { Stage III } \\
\mathrm{T} 4 \text {, any N, M0 }\end{array}$ & $\begin{array}{c}\text { Stage IV } \\
\text { Any T, N } \\
\text { M1 }\end{array}$ \\
\hline
\end{tabular}

little to no mitotic activity. Included in the baseline work-up of PETs is Ki-67, as the Ki-67 index (the percentage of positive tumor cells in the area of highest nuclear labeling) separates benign, welldifferentiated NET $(<2 \%)$ from those of uncertain behavior $(\geqslant 2 \%)$.

Owing to the rarity of these tumors, data concerning prognostic factors and survival are based mainly on reports of small series with variable diagnoses, diagnostic criteria, therapies and other treatment modalities. ${ }^{18}$ Median survival statistics range from 38 to 104 months $^{19}$ and 5-year survival rates are reported at $40-60 \% .{ }^{19}$ The most valuable prognostic variables include clinical parameters, such as the success of primary surgery, the presence of distant metastases and the manifestation of endocrine symptoms; the only pathological prognostic variables of importance are the presence of tumor necrosis, the mitotic count and the Ki-67/MIB-1labeling index.

The application of a similar three-tier classification system to the various areas of the GEP has been proposed. ${ }^{4,20}$ Unfortunately, these standards have not been as well accepted by pulmonary pathologists, creating confusion in terminology and classification.

\section{Staging}

In 2006, a tumor-node-metastasis staging system was proposed for PETs by a large consensus group, ${ }^{21}$ and recent reports validate the clinical relevance of this system. ${ }^{19,22}$ Recent updates have been made in the seventh version of the Cancer Staging Protocols endorsed by the American Joint Committee on Cancer and International Union Against Cancer $^{23}$ and these are reflected in the new CAP synoptic reports available at http://www.cap.org/apps/cap. portal? nfpb $=$ true\&cntvwrPtlt_actionOverride $=\%$ 2 Fportlets $\% 2$ FcontentViewer\% 2 Fshow\&_window Label $=$ cntvwrPtlt\&cntvwrPtlt\%7BactionForm.content Reference $\% 7 \mathrm{D}=$ committees $\% 2$ Fcancer $\% 2$ Fcancer protocols $\% 2$ Fprotocols_index.html\&_state $=$ maximized \&_pageLabel = cntvwr. The important staging criteria are listed in Table 2. The major changes from the previous staging criteria involve (i) $\mathrm{T} 3$ and $\mathrm{T} 4$ classification: in the previous version, tumor invading adjacent organs (stomach, spleen, colon, adrenal gland) were classified as T4, whereas in the new version, local invasion without involvement of the celiac axis or superior mesenteric artery qualifies as T3, and (ii) staging: former stage IIa is now Ib, former IIb is IIa, the new IIb is for T1-3 with any N (no N positive tumors were stage II previously) and the former IIIa that classified T4 No tumors is replaced with a single stage III for T4, any N. These changes reflect the fact that primary tumor size over $2 \mathrm{~cm}$ alone does not create a stage II patient, whereas involvement of the celiac axis or superior mesenteric artery renders a tumor unresectable; therefore, stage III and stage II is now defined as patients with locally invasive tumors or with regional lymph node metastases.

\section{Pathobiology and molecular genetics}

PETs are thought to arise from pluripotent stem cells in ductal epithelium. This contrasts with animal 
models in which endocrine cells exhibit transformation within mature islets, ${ }^{24}$ and it remains to be proven whether one or both sites of tumorigenesis occur in human beings. There is certainly evidence of proliferation of endocrine cells from pancreatic ductular proliferations, a phenomenon known as 'nesidioblastosis,' also known as 'ductulo-insular complexes,' in several human conditions, including pancreatitis and ductal obstruction as well as in patients with genetic predisposition to PET development (see below). In the setting of familial PETs, there is also evidence of islet hyperplasia and dysplasia, the latter characterized by cytologic and architectural atypia as defined by the relative numbers and spatial relationships of the four cells types that comprise the islets, suggesting that both mechanisms may give rise to neoplastic lesions.

Chromosomal instability has been implicated in tumor progression. Comparative genomic hybridization studies have shown losses of genetic material more often than gains, and amplifications are uncommon, ${ }^{5}$ and the number of genomic changes per tumor is associated with tumor size and disease stage, indicating that genetic alterations accumulate during tumor progression. Losses of chromosome 1 and $11 \mathrm{q}$ and gains on $9 \mathrm{q}$ appear to be early events that are already identified in small tumors. Metastases show prevalent gains of chromosomes 4 and 7 and loss of 21q, implying that these alterations may contribute to tumor dissemination.

The common oncogenes and tumor suppressor genes, including $K$-ras, TP53, Rb, PTEN, DPC4, $C D K N 2 A / p 16$, von Hippel-Lindau (VHL), RET, $B R A F, S M A D 3$ and the DNA mismatch repair genes, are not implicated in the molecular pathogenesis of these tumors, as mutations and/or loss of heterozygosity are either not found or are extremely rare in sporadic tumors. ${ }^{5} \beta$-catenin and alterations of the wnt signaling pathway are more commonly encountered in NETs of the GI tract than in PETs.

The well-characterized subset of PETs that is associated with inherited genetic predisposition syndromes may shed light on the molecular alterations underlying these lesions. There are four wellrecognized familial or inherited scenarios. PETs associated with syndromes are obviously associated with characteristic genetic abnormalities and four such syndromes exist: multiple endocrine neoplasia (MEN) type 1 (MEN-1 gene), VHL disease (VHL gene), neurofibromatosis type $1(N F-1$ gene) and tuberous sclerosis complexes 1 and 2 (TSC1 and 2 genes). Somatic mutations of the $M E N-1$ gene are identified in about $20 \%$ of sporadic PETs and up to $68 \%$ harbor losses of $11 \mathrm{q} 13$ and/or more distal parts of the long arm of chromosome $11,{ }^{25-28}$ suggesting that another as yet unknown tumor suppressor gene might be involved.

Rare familial cases of insulin-producing PET have been described, but the genetic basis of these tumors has not been identified. ${ }^{29}$

\section{MEN Syndrome, Type 1}

$M E N-1$ gene is an autosomal-dominant condition because of germline mutations of the MEN-1 tumor suppressor gene located on chromosome $11 \mathrm{q} 133^{30,31}$ $M E N-1$ encodes a 610 amino-acid nuclear protein, menin, whose functions have not been fully elucidated. Menin interacts with a large number of proteins that are implicated in transcriptional regulation, genomic stability, cell division and cell cycle control. The majority of MEN-1 families have heterozygous germline mutations scattered throughout the MEN-1 protein-coding region. Numerous unique mutations have been described, but most (about $70 \%$ ) involve truncation mutations, resulting from frameshift (deletions, insertions, deletion/insertion or splice site defects) and nonsense mutations. Loss of the normal allele results in loss of expression of menin and tumorigenesis in affected tissues. The disorder has $94 \%$ penetrance with manifestation of the associated pathology by the age of 50 years. PETs are diagnosed clinically in $>60 \%$ of patients with MEN-1, but that number approaches $100 \%$ in autopsy studies. ${ }^{5}$ Parathyroid and pituitary lesions usually manifest before pancreatic lesions are found. No correlation has thus far been shown between specific genetic aberrations and the clinical features in MEN-1 patients.

MEN-1 involvement of the pancreas initially involves the development of multiple, small PETs, often microadenomas, associated with foci of nesidioblastosis (Figure 4a) or ductulo-insular complexes. $^{32-35}$ A curious feature is the presence of peliosis in islets (Figure 4b) and adenomas. ${ }^{33}$ Islet dysplasia, defined as normal-sized or slightly enlarged islets containing cells with mild cytologic atypia, is readily confirmed by immunohistochemistry that shows loss of the normal spatial and quantitative arrangement of the four main cell types (Figure 5). Once islet dysplasia attains a size of $0.5 \mathrm{~mm}$, it is classified as microadenoma. Islet dysplasia is most frequently associated with MEN type 1. Of the functional MEN-associated PETs, 50\% are gastrin-producing and $20 \%$ are insulin-producing tumors. MEN-1 is diagnosed in about $25 \%$ of patients who have a gastrinoma and in about $5 \%$ of those who have an insulin-producing PET. It is important to note that in MEN-1, duodenal gastrinproducing tumors are more common than those arising in the pancreas. In contrast to sporadic PETs, those associated with MEN-1 tend to present at an earlier age (30-50 years), have a higher rate of postoperative recurrence and are a common cause of death in these patients.

MEN-1-associated PETs display a wide variety of molecular abnormalities including chromosomal loss, chromosomal loss with duplication, mitotic recombination or point mutation of the wild-type allele. Similar to their sporadic counterparts, they exhibit inter- and intra-tumoral genetic heterogeneity indicating chromosomal instability. ${ }^{36,37}$ 

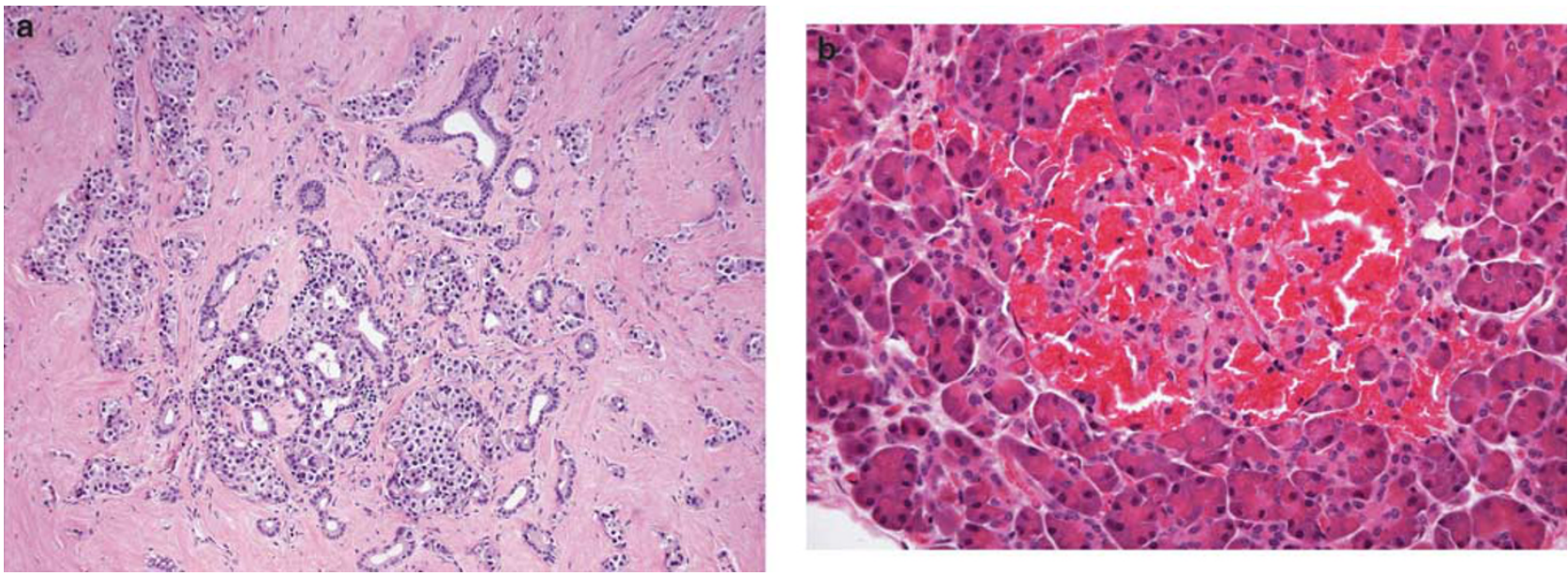

Figure 4 The pancreas in MEN-1. Patients with MEN-1 have multiple pancreatic endocrine tumors associated with (a) nesidioblastosis, proliferation of endocrine elements from ducts and (b) peliosis in islets (shown) and adenomas (not shown).
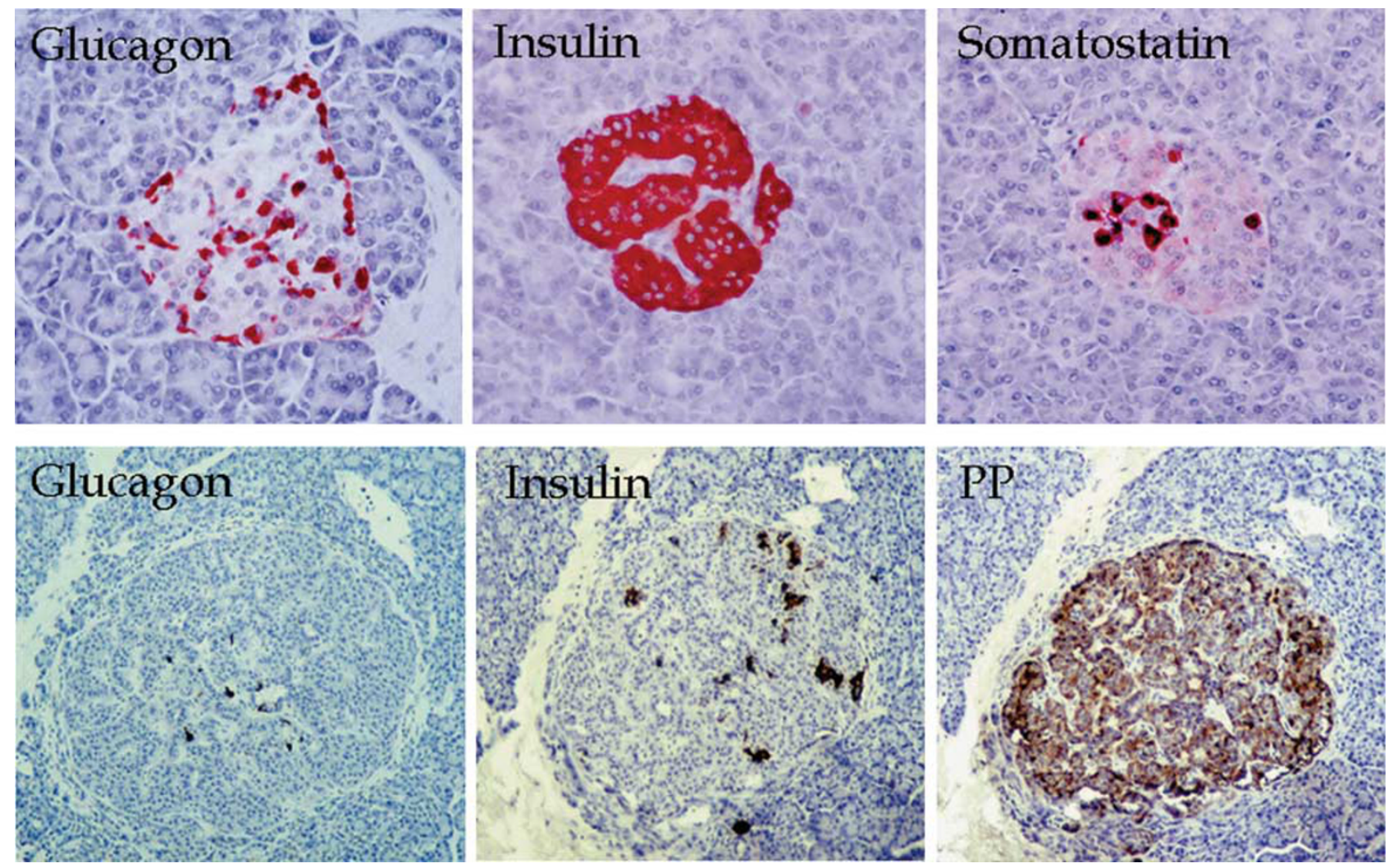

Figure 5 Islet dysplasia in MEN-1. Slightly enlarged islets contain cells with mild cytologic atypia that are confirmed by immunohistochemistry to show loss of the normal spatial and quantitative arrangement of the four main cell types. Once islet dysplasia attains a size of $0.5 \mathrm{~mm}$, it is classified as microadenoma.

\section{VHL Disease}

VHL disease is an autosomal-dominant condition because of deletions or mutations in a tumor suppressor gene located on chromosome $3 p 25.5{ }^{38}$ The VHL gene encodes a 232 amino-acid protein, pVHL, which has several functions including regulation of ubiquitination of the hypoxia-induci- ble factors HIF1 and 2, resulting in upregulation of angiogenic, growth and mitogenic factors including VEGF, PDGF $\beta$, TGF $\alpha$ and erythropoietin substances. ${ }^{38}$ As with MEN-1, loss of the normal allele results in tumorigenesis in affected tissues. The disease is characterized by retinal and central nervous system hemangioblastomas, cysts in the kidney, epididymis (papillary cystadenoma) and 
liver, hemangiomas of the adrenal, liver and lung, renal cell carcinoma, pheochromocytoma and endolymphatic sac tumors. In contrast to MEN-1, there is significant correlation between genetic mutation and clinical manifestations of this disease ${ }^{38}$ especially with regard to the development of pheochromocytomas. Missense mutations are found more frequently in patients with pheochromocytoma (so-called type 2), whereas those without (type 1) have large deletions or premature truncation mutations. ${ }^{38}$

Pancreatic pathology in VHL usually takes the form of benign cysts and microcystic or serous adenomas, which occur in 35-70\% of VHL patients. PETs are less common, but occur in $2-12 \%$ of patients. $^{39,40}$ They occur in young patients, are multiple and located anywhere in the pancreas, are said to be functionally inactive, although immunohistochemistry does show focal positivity for pancreatic polypeptide, somatostatin, glucagon and/or insulin in $30-40 \%$ of cases. They were initially reported to not be associated with either microadenomas (endocrine cell foci $<0.5 \mathrm{~cm}$ in diameter) or nesidioblastosis. ${ }^{39}$ However, we have observed these findings in association with VHL. ${ }^{41,42}$ VHL-associated PETs tend to be arranged in trabeculae, glandular configurations and solid foci. Characteristically, up to $60 \%$ of the tumors contain clear cells or multi-vacuolated lipid-rich cells in varying proportions.

There are no data on the VHL genotypic predisposition to PETs. The pancreatic tumors in patients with this disorder have been documented to exhibit loss of heterozygosity of the normal VHL allele. ${ }^{39}$

\section{Neurofibromatosis Type I}

$N F-1$ is a relatively common disorder occurring in 14000-5000 live births and is due to alterations in the $N F-1$ gene on chromosome 17q11.2, which encodes a 2485 amino-acid protein, neurofibromin. ${ }^{43,44} \mathrm{Neu}-$ rofibromin is widely expressed in the nervous system where it acts as a tumor suppressor, affecting cell proliferation/growth and signaling by regulating the activation of p21 ras by its Ras GTPase proteinactivating activity, binding microtubules, modulating adenylate cyclase activity, interacting with the cellular cytoskeleton and by interacting through a signaling pathway with tuberin (the TSC2 gene product) that regulates mTOR, a serine-threonine kinase that is involved in cell growth and proliferation. Alterations include nonsense, frameshift and splice mutations, partial or complete deletions and translocation. De novo mutations account for $50 \%$ of all cases; the remainder are inherited as an autosomal-dominant syndrome with complete penetrance and variable expression. ${ }^{45}$ Invariably, signs and/or symptoms present by 5 years of age. The commonest manifestations are neurofibromas and café-au-lait skin macules as well as functional neurological deficits and epilepsy; other lesions include ganglioneuromas, gastrointestinal stromal tumors and interstitial cell of Cajal hyperplasia. Endocrine involvement, while rare, is manifest as pheochromocytomas, gastrointestinal NETs and precocious puberty as well as PETs.

Duodenal somatostatinomas occur in NF-1 patients; in fact, NF-1 accounted for $48 \%$ of duodenal somatostatinomas reported in the literature in one review. ${ }^{46}$ Pancreatic somatostatinomas are more rare $^{46}$ (16 times less common than duodenal somatostinomas) and occasional NF-1 patients with pancreatic gastrinoma, insulinoma and non-functioning PET have been reported. ${ }^{47}$

\section{Tuberous Sclerosis}

$T S$ is an autosomal-dominant, neurocutaneous multisystem disorder that is due to mutations in one of two genes, the TSC1 gene at 9q34 that encodes hamartin, or TSC2 at 16p13.3 that encodes tuberin. The two proteins produced by these genes dimerize and have a pivotal role in the phosphoinositide 3-kinase signaling pathway, and also are implicated in regulation of the small GTPase, rheb, which is involved in regulating mTOR activity. Most cases are due to sporadic de novo mutations, with no family history of the disease. Manifestations are usually apparent shortly after birth. The disorder is characterized by hamartomas in almost every organ, but the main organs involved are the brain, skin, eyes, heart, kidneys, lungs and skeleton. Disabling neurological features include epilepsy, mental retardation and autism.

Rare PETs have been reported in patients with TS and it is not clear if there is a causal or a casual association. Malignant PETs have been described in children $^{48,49}$ and functional PETs have been reported to produce insulin ${ }^{50,51}$ and gastrin. ${ }^{52}$ Hamartin is highly expressed in normal islet cells, ${ }^{53}$ so it is not difficult to imagine that loss of this tumor suppressor may have an etiologic role in these lesions.

\section{Predictive and prognostic markers}

\section{Somatostatin Receptor Expression}

Somatostatin was identified as an important inhibitory hormone, initially for growth hormone secretion. Its expression in the pancreas and gut was recognized early. Somatostatin binds to a family of five G-protein-coupled receptors that inhibit adenylate cyclase activity. The ubiquitous expression of somatostatin receptors (SSTRs) in $80-90 \%$ of NETs, as shown by autoradiography, octreotide scintigraphy and later by immunocytochemistry, led to the application of this inhibitor in the treatment of NETs almost 30 years ago. The clinical use of native somatostatin was hampered by its short half-life of only $2 \mathrm{~min}$, which required frequent intravenous 
infusion. The development of long-acting somatostatin analogs-mainly octreotide and lanreotidewhich contain the four amino-acid sequence presumed to be essential for biological activity has allowed more widespread clinical application.

Somatostatin analog therapy is efficacious in reducing hormone excess. Significant tumor reduction is not seen, but antiproliferative activity result in tumor stabilization. The clinically available somatostatin analogs bind with high affinity to SSTR2 and SSTR5 and with lower affinity to SSTR3. The biochemical responses are believed to be mediated through SSTR2, whereas the antiproliferative effects are believed to be mediated through SSTR2 and SSTR5, whereas SSTR3 is thought to mediate induction of apoptosis. Anti-angiogenic and immunomodulatory effects have also been described..$^{54}$ Recently, somatostatin analogs labeled with radioactive isotopes have been developed for therapeutic use. ${ }^{111}$ In-DTPA-octreotide was initially used and provided symptomatic and biochemical responses with stabilization of tumor growth in patients with intense uptake in the tumors. Currently, other more potent isotopes (90Y and $177 \mathrm{Lu}$ ) are being tested in phase II trials, and preliminary data indicate tumor responses in $>30 \%$ of cases with relatively long duration. ${ }^{6}$ These important advances suggest that the immunohistochemical profile of SSTRs in PETs $^{55}$ may have clinical relevance for therapeutic decisions.

\section{Markers of Aggressive Behavior}

Markers of aggressive behavior are needed to distinguish lesions that are likely to be cured by surgery from those that will recur and metastasize, and ultimately cause the demise of the patient. Overexpression of mRNA for the epidermal growth factor and hepatocyte growth factor receptors has been reported in a subpopulation of pancreatic gastrinomas that exhibit more aggressive behavior. ${ }^{56}$ Other markers that predict more aggressive malignancy include cytokeratin 19, a marker that has been shown to have independent prognostic value in PETs and should form part of the routine immunohistochemical work-up of these tumors, ${ }^{57-59}$ E-cadherin that appears to be downregulated or alternatively expressed with aberrant nuclear localization in invasive tumors ${ }^{60}$ and CEACAM1 that is overexpressed in more aggressive and malignant lesions. ${ }^{61}$ The identification of HER-2/neu amplification has raised the possibility of new therapeutic approaches in the management of patients with these lesions, ${ }^{62}$ but this finding has not been confirmed and no clinical data to prove response to Herceptin are available.

The impact of genetic alterations is not restricted to mutations of oncogenes and tumor suppressor genes. Polymorphisms can modify the risk of development of tumors or the behavior of established neoplasia. One such polymorphism is in the gene that encodes fibroblast growth factor receptor 4 (FGFR4). An arginine substitution for glycine at codon 388 of the FGFR4 gene has been shown to predict more aggressive behavior of breast, colon and squamous carcinomas of the head and neck. ${ }^{63-65}$ Recent data indicate that this polymorphism independently predicts aggressive behavior with hepatic metastasis in PETs. ${ }^{66}$ This may be at least partially mediated through the receptor's interactions with $\mathrm{N}$-CAM and N-cadherin that have been shown to have a role in progression of PETs in a mouse model. ${ }^{67}$

\section{Conclusions}

Endocrine tumors of the pancreas represent a relatively rare group of lesions that pose diagnostic and therapeutic challenges. These tumors are clinically and pathologically heterogeneous; they often present with obscure symptoms that lead to delays in diagnosis of years. ${ }^{68}$ The definition of malignancy is difficult and often impossible based on conventional histology, and the management of patients with lesions of uncertain malignant potential is controversial. Once malignancy is established, they offer a unique target for specific therapies that may hold promise, but remain to be validated in large series and multiple centers. The genetic and epigenetic alterations that underlie their development are largely unknown. Genetic predisposition underlies a proportion of these tumors, but the genetics of those syndromes has not clarified the basis of the more common sporadic tumors. Interesting recent data suggest that they represent one of the few cancers that are increasing in incidence. ${ }^{69}$ These features should incite an interest in studying them in further depth. Collaborative studies of multidisciplinary teams in multiple centers will be required to achieve major advances in the near future.

\section{Disclosure/conflict of interest}

The author declares no conflict of interest.

\section{References}

1 DeLellis RA, Tischler AS. The dispersed neuroendocrine cell system In: Kovacs K, Asa SL (eds). Functional Endocrine Pathology. Blackwell: Boston, 1998, pp 529-549.

2 Oberndorfer S. Karzinoide tumoren des dünndarms. Frankfurter Zeitschrift für Pathologie 1907;1:425-432.

3 Kloppel G, Rindi G, Anlauf M, et al. Site-specific biology and pathology of gastroenteropancreatic neuroendocrine tumors. Virchows Arch 2007;451 (Suppl 1):S9-S27.

4 Kloppel G, Perren A, Heitz PU. The gastroenteropancreatic neuroendocrine cell system and its tumors: the 
WHO classification. Ann NY Acad Sci 2004;1014: 13-27.

5 DeLellis RA, Lloyd RV, Heitz PU, et al. Pathology and Genetics of Tumours of Endocrine Organs. IARC Press: Lyons, France, 2004.

6 Oberg K, Eriksson B. Endocrine tumours of the pancreas. Best Pract Res Clin Gastroenterol 2005; 19:753-781.

7 Grimelius L, Hultquist GT, Stenkvist B. Cytological differentiation of asymptomatic pancreatic islet cell tumours in autopsy material. Virchows Arch A Pathol Anat Histol 1975;365:275-288.

8 Hruban RH, Pitman MB, Klimstra DS. Tumors of the Pancreas 4th Series, Fascicle 6 ed. Armed Forces Institute of Pathology: Washington, DC, 2007.

9 Chetty R, Asa SL, Adsay NV. Pancreatic endocrine tumors with ductules. Am J Surg Pathol 2005;29: 136-137.

10 Chetty R, Serra S, Asa SL, et al. Pancreatic endocrine tumour with ductules: further observations of an unusual histological subtype. Pathol 2006;38:5-9.

11 Serra S, Asa SL, Chetty R. Intracytoplasmic inclusions (including the so-called 'rhabdoid' phenotype) in pancreatic endocrine tumors. Endocr Pathol 2006;17:75-81.

12 Chetty R, Asa SL. Pancreatic endocrine tumour with cytoplasmic keratin whorls. Is the term 'rhabdoid' appropriate? J Clin Pathol 2004;57:1106-1110.

13 Asa SL, Ezzat S. Endocrine organs In: Allison MR (ed). The Cancer Handbook. John Wiley and Sons Ltd: West Sussex, England, 2007, pp 611-623.

14 Eriksson B, Arnberg H, Oberg K, et al. Chromogranins-new sensitive markers for neuroendocrine tumors. Acta Oncol 1989;28:325-329.

15 Tanimoto A, Matsuki Y, Tomita T, et al. Histidine decarboxylase expression in pancreatic endocrine cells and related tumors. Pathol Int 2004;54: 408-412.

16 Srivastava A, Padilla O, Fischer-Colbrie R, et al. Neuroendocrine secretory protein-55 (NESP-55) expression discriminates pancreatic endocrine tumors and pheochromocytomas from gastrointestinal and pulmonary carcinoids. Am J Surg Pathol 2004; 28:1371-1378.

17 Wick MR. Neuroendocrine neoplasia. Current concepts. Am J Clin Pathol 2000;113:331-335.

18 La Rosa S, Sessa F, Capella C, et al. Prognostic criteria in nonfunctioning pancreatic endocrine tumours. Virchows Arch 1996;429:323-333.

19 Ekeblad S, Skogseid B, Dunder K, et al. Prognostic factors and survival in 324 patients with pancreatic endocrine tumor treated at a single institution. Clin Cancer Res 2008;14:7798-7803.

20 Kloppel G, Couvelard A, Perren A, et al. ENETS Consensus Guidelines for the Standards of Care in Neuroendocrine Tumors: towards a standardized approach to the diagnosis of gastroenteropancreatic neuroendocrine tumors and their prognostic stratification. Neuroendocrinology 2009;90:162-166.

21 Rindi G, Kloppel G, Alhman H, et al. TNM staging of foregut (neuro)endocrine tumors: a consensus proposal including a grading system. Virchows Arch 2006; 449:395-401.

22 Fischer L, Kleeff J, Esposito I, et al. Clinical outcome and long-term survival in 118 consecutive patients with neuroendocrine tumours of the pancreas. Br J Surg 2008;95:627-635.
23 Edge SB, Byrd DR, Carducci MA, et al. AJCC Cancer Staging Manual 7 edn. Springer: New York, NY, 2009.

24 Murphy D, Bishop A, Rindi G, et al. Mice transgenic for a vasopressin-SV40 hybrid oncogene develop tumors of the endocrine pancreas and the anterior pituitary: a possible model for human multiple endocrine neoplasia type 1. Am J Pathol 1987;129:552-566.

25 Zhuang Z, Vortmeyer AO, Pack S, et al. Somatic mutations of the MEN1 tumor suppressor gene in sporadic gastrinomas and insulinomas. Cancer Res (Baltimore) 1997;57:4682-4686.

26 Toliat M, Berger W, Ropers HH, et al. Mutations in the MEN1 gene in sporadic neuroendocrine tumours of gastroenteropancreatic system. Lancet 1997;350: 1223.

27 Debelenko LV, Zhuang Z, Emmert-Buck MR, et al. Allelic deletions on chromosome 11q13 in multiple endocrine neoplasia type 1- associated and sporadic gastrinomas and pancreatic endocrine tumors. Cancer Res 1997;57:2238-2243.

28 Hessman O, Lindberg D, Skogseid B, et al. Mutation of the multiple endocrine neoplasia type 1 gene in nonfamilial, malignant tumors of the endocrine pancreas. Cancer Res 1998;58:377-379.

29 Maioli M, Ciccarese M, Pacifico A, et al. Familial insulinoma: description of two cases. Acta Diabetol 1992;29:38-40.

30 Chandrasekharappa SC, Guru SC, Manickam P, et al. Positional cloning of the gene for multiple endocrine neoplasia-type 1. Science 1997;276:404-407.

31 Agarwal SK, Kester MB, Debelenko LV, et al. Germline mutations of the MEN1 gene in familial multiple endocrine neoplasia type 1 and related states. Hum Mol Genet 1997;6:1169-1175.

32 Lubensky IA. Endocrine Pancreas In: LiVolsi VA, Asa SL (eds). Endocrine Pathology. Churchill Livingstone: Philadelphia, PA, 2002, pp 205-235.

33 Kovacs K, Horvath E, Asa SL, et al. Microscopic peliosis of pancreatic islets in a woman with MEN-1 syndrome. Arch Pathol Lab Med 1986;110:607-610.

34 Asa SL, Singer W, Kovacs K, et al. Pancreatic endocrine tumour producing growth hormone-releasing hormone associated with multiple endocrine neoplasia type I syndrome. Acta Endocrinol (Copenh) 1987;115:331-337.

35 Asa SL. The endocrine pancreas and its tumors. Endocr Pathol 1993;4:120-130.

36 Hessman O, Lindberg D, Einarsson A, et al. Genetic alterations on 3p, 11q13, and 18q in nonfamilial and MEN 1-associated pancreatic endocrine tumors. Genes Chromosomes Cancer 1999;26:258-264.

37 Hessman O, Skogseid B, Westin G, et al. Multiple allelic deletions and intratumoral genetic heterogeneity in men1 pancreatic tumors. J Clin Endocrinol Metab 2001;86:1355-1361.

38 Kaelin Jr WG. Molecular basis of the VHL hereditary cancer syndrome. Nat Rev Cancer 2002;2:673-682.

39 Lubensky IA, Pack S, Ault D, et al. Multiple neuroendocrine tumors of the pancreas in von Hippel-Lindau disease patients: histopathological and molecular genetic analysis. Am J Pathol 1998;153:223-231.

40 Hammel PR, Vilgrain V, Terris B, et al. Pancreatic involvement in von Hippel-Lindau disease. The Groupe Francophone d'Etude de la Maladie de von Hippel-Lindau. Gastroenterology 2000;119:1087-1095.

41 Chetty R, Kennedy M, Ezzat S, et al. Pancreatic endocrine pathology in von Hippel-Lindau disease: 
an expanding spectrum of lesions. Endocr Pathol 2004;15:141-148.

42 Chetty R, Ezzat S, Asa SL. Microadenomatosis of the pancreas in von Hippel-Lindau disease. Am J Surg Pathol 2006;30:1630-1631.

$43 \mathrm{Xu}$ GF, O'Connell P, Viskochil D, et al. The neurofibromatosis type 1 gene encodes a protein related to GAP. Cell 1990;62:599-608.

44 Ballester R, Marchuk D, Boguski M, et al. The NF1 locus encodes a protein functionally related to mammalian GAP and yeast IRA proteins. Cell 1990;63: 851-859.

45 Ferner RE. Neurofibromatosis 1 and neurofibromatosis 2: a twenty first century perspective. Lancet Neurol 2007;6:340-351.

46 Mao C, Shah A, Hanson DJ, et al. Von Recklinghausen's disease associated with duodenal somatostatinoma: contrast of duodenal versus pancreatic somatostatinomas. J Surg Oncol 1995;59:67-73.

47 Jensen RT, Berna MJ, Bingham DB, et al. Inherited pancreatic endocrine tumor syndromes: advances in molecular pathogenesis, diagnosis, management, and controversies. Cancer 2008;113(7 Suppl):1807-1843.

48 Verhoef S, Diemen-Steenvoorde R, Akkersdijk WL, et al. Malignant pancreatic tumour within the spectrum of tuberous sclerosis complex in childhood. Eur J Pediatr 1999;158:284-287.

49 Francalanci P, Diomedi-Camassei F, Purificato C, et al. Malignant pancreatic endocrine tumor in a child with tuberous sclerosis. Am J Surg Pathol 2003; 27:1386-1389.

$50 \mathrm{Kim}$ H, Kerr A, Morehouse H. The association between tuberous sclerosis and insulinoma. AJNR Am J Neuroradiol 1995;16:1543-1544.

51 Eledrisi MS, Stuart CA, Alshanti M. Insulinoma in a patient with tuberous sclerosis: is there an association? Endocr Pract 2002;8:109-112.

52 Schwarzkopf G, Pfisterer J. Metastasizing gastrinoma and tuberous sclerosis complex. Association or coincidence? Zentralbl Pathol 1994;139:477-481.

53 Plank TL, Logginidou H, Klein-Szanto A, et al. The expression of hamartin, the product of the TSC1 gene, in normal human tissues and in TSC1- and TSC2linked angiomyolipomas. Mod Pathol 1999;12: 539-545.

54 Lamberts SWJ, Krenning EP, Reubi JC. The role of somatostatin and its analogs in the diagnosis and treatment of tumors. Endocr Rev 1991;12:450-482.

55 Papotti M, Bongiovanni M, Volante M, et al. Expression of somatostatin receptor types 1-5 in 81 cases of gastrointestinal and pancreatic endocrine tumors. A correlative immunohistochemical and reverse-transcriptase polymerase chain reaction analysis. Virchows Arch 2002;440:461-475.
56 Peghini PL, Iwamoto M, Raffeld M, et al. Overexpression of epidermal growth factor and hepatocyte growth factor receptors in a proportion of gastrinomas correlates with aggressive growth and lower curability. Clin Cancer Res 2002;8:2273-2285.

57 Deshpande V, Fernandez-del Castillo C, Muzikansky $\mathrm{A}$, et al. Cytokeratin 19 is a powerful predictor of survival in pancreatic endocrine tumors. Am J Surg Pathol 2004;28:1145-1153.

58 Ali A, Serra S, Asa SL, et al. The predictive value of CK19 and CD99 in pancreatic endocrine tumors. Am J Surg Pathol 2006;30:1588-1594.

59 Schmitt AM, Anlauf M, Rousson V, et al. WHO 2004 criteria and CK19 are reliable prognostic markers in pancreatic endocrine tumors. Am J Surg Pathol 2007;31:1677-1682.

60 Chetty R, Serra S, Asa SL. Loss of membrane localization and aberrant nuclear E-cadherin expression correlates with invasion in pancreatic endocrine tumors. Am J Surg Pathol 2008;32:413-419.

61 Serra S, Asa SL, Bamberger AM, et al. CEACAM1 expression in pancreatic endocrine tumors. Appl Immunohistochem Mol Morphol 2009;17:286-293.

62 Evers BM, Rady PL, Sandoval K, et al. Gastrinomas demonstrate amplification of the HER-2/neu protooncogene. Ann Surg 1994;219:596-601.

63 Bange J, Prechtl D, Cheburkin Y, et al. Cancer progression and tumor cell motility are associated with the FGFR4 $\operatorname{Arg}(388)$ allele. Cancer Res 2002;62: 840-847.

64 Streit S, Bange J, Fichtner A, et al. Involvement of the FGFR4 Arg388 allele in head and neck squamous cell carcinoma. Int J Cancer 2004;111:213-217.

65 Thussbas C, Nahrig J, Streit S, et al. FGFR4 Arg388 allele is associated with resistance to adjuvant therapy in primary breast cancer. J Clin Oncol 2006;24: 3747-3755.

66 Serra S, Zheng L, Ezzat S, et al. The FGFR4-R388 transmembrane polymorphism preferentially recruits cSrc to constitutively activate STAT3 in promoting pancreatic neuroendocrine tumor metastasis (submitted).

67 Cavallaro U, Niedermeyer J, Fuxa M, et al. N-CAM modulates tumour-cell adhesion to matrix by inducing FGF-receptor signalling. Nat Cell Biol 2001;3:650-657.

68 Modlin IM, Moss SF, Chung DC, et al. Priorities for improving the management of gastroenteropancreatic neuroendocrine tumors. J Natl Cancer Inst 2008; 100:1282-1289.

69 Clegg LX, Reichman ME, Miller BA, et al. Impact of socioeconomic status on cancer incidence and stage at diagnosis: selected findings from the surveillance, epidemiology, and end results: National Longitudinal Mortality Study. Cancer Causes Control 2009;20:417-435. 